\title{
IUS ET SCIENTIA
}

2021 • Vol. 7 • No 1• ISSN 2444-8478

https://editorial.us.es/es/revistas/ius-et-scientia

https://dx.doi.org/10.12795/IETSCIENTIA • @ Editorial Universidad de Sevilla 2021

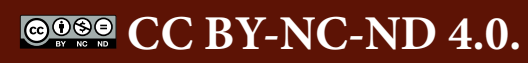

\section{Inteligencia Artificial y derecho. Ni dioses ni bestias ni cíborgs: homo juridicus}

\author{
ARTIFICIAL INTELLIGENCE AND LAW. NEITHER GODS NOR BEASTS NOR \\ CYBORGS: HOMO JURIDICUS
}

\author{
Gabriel R. Juan \\ Doctor en Ciencias Jurídicas y Sociales \\ Profesor universitario de grado y posgrado. \\ Universidad Nacional de Cuyo (Argentina). \\ gabrieljuan@estudiojuan.com.ar @ 0000-0003-4901-7500
}

Recibido: 21 de mayo de 2021 | Aceptado: 03 de junio de 2021

\section{RESUMEN}

El presente trabajo parte de una defensa del Derecho de los sistemas jurídicos constitucionalizados, por el lugar central que otorga a los derechos humanos, cuya base es la dignidad de la persona humana. Destaca asimismo que la aspiración de realización del valor justicia nos caracteriza como Homo Juridicus. Todo lo cual encuentra justificación en una ética humanista que, en tanto integrante de una cultura jurídica, concuerda con el objeto de estudio del Bioderecho Internacional.

En ese marco, luego de identificar los problemas y riesgos de la Inteligencia Artificial, de conceptualizar y caracterizar la posición transhumanista, mediante un abordaje ético se contrapone esta última visión con aquella biojurídica. La conclusión es que esta última es la única que proporciona una adecuada justificación a las acciones y límites normativos.

\footnotetext{
ABSTRACT

This papers takes into consideration the defense of the Law of the constitutionalized legal systems due to the fact it provides to human rights the basis which is the dignity of every human being. It also highlights that when achieving justice value we are characterized like Homo Juridicus.

All of which is justified by a humanistic ethic that, as part of a legal culture, is consistent with the object of study of international biolaw.

In this context the problems and risks of Artificial Intelligence are analyzed in contrast to transhumanism with a humanist ethic.
}

\section{PALABRAS CLAVE}

Inteligencia Artificial

Bioderecho

Filosofía del derecho

Ética

Transhumanismo

\section{KEYWORDS}

Artificial Intelligence

Biolaw

Philosophy of Law

Ethic

Transhumanism 


\section{INTRODUCCIÓN}

El presente trabajo es una apología del Derecho. ${ }^{1}$ Para ser más específico, de una cultura jurídica que, en tanto práctica social y dialógica, promueven los sistemas jurídicos constitucionalizados. Su nervio principal es el derecho internacional de derechos humanos, cuya base es la dignidad de la persona humana. La aspiración de realización del valor justicia, que es el rasgo que identifica al Derecho y la cultura jurídica, resulta un dato antropológico fundamental. En palabras de Alain Supiot, es lo que nos caracteriza como homo juridicus; es la manera que hemos encontrado para vincular las emociones biológica y simbólica, ambas constitutivas del ser humano. El Derecho se constituye así en el vínculo entre la infinitud del universo mental y la finitud de la experiencia física (Supiot, 2012, 11).

Éste es entonces el punto de partida "humanista", desde el cual se reflexiona sobre el impacto de las tecnologías de la información (TIC) en general y la Inteligencia Artificial (IA) en particular. También sobre los avances biotecnológicos (Ingeniería Genética), en razón de su influencia en las corrientes de pensamiento "no humanistas".

Las problemáticas vinculadas con la Inteligencia Artificial se remontan treinta años atrás, a comienzos de los noventa del siglo pasado, cuando se produjo el estallido de la revolución informática. Su onda expansiva fue de tal magnitud, que aún continúa causando perplejidades en el Derecho. Una de ellas, quizá la más significativa, se refiere al impacto sobre las relaciones intersubjetivas, cuando son mediadas por el acontecimiento digital. En los hechos, esta situación representó un corrimiento de las fronteras que separan lo íntimo de lo privado y lo público. Nada indica que en los próximos años esta confusión de esferas cese o se debilite; antes bien lo contrario, pues una de las características del fenómeno tecnológico es su capacidad intrínseca de multiplicarse en sus potencialidades y efectos.

Por esta misma razón, es difícil predecir cómo será el corpus jurídico que nos regirá en el futuro; ni los juristas, ni los estudiosos de otras disciplinas sociales o humanistas (sociólogos, antropólogos, filósofos, historiadores), ni siquiera los propios tecnocientíficos están en condiciones de prever cuál será la dinámica futura de las tecnologías de la información. En consecuencia, tampoco es posible anticipar el impacto sobre las relaciones humanas. Intentar conocer cuál será el comportamiento de la "infotecnología" (Harari, 2020, 14) en las próximas décadas excede nuestra capacidad de previsión. Si se comparte este diagnóstico, podemos convenir que lo recomendable es no esbozar pronóstico alguno.

Pero éste no es el problema que atañe a los estudios iusfilosóficos. En definitiva, su función no es anticipar cómo será o cómo debería ser el Derecho de una comunidad global, hipotética y futura, sino analizar con criterio totalizador y crítico qué es lo que sucede aquí y ahora. La finalidad de este artículo, entonces, sigue esta última dirección.

En tal sentido, comienzo por conceptualizar la Inteligencia Artificial y el Derecho aplicable, para luego resaltar críticamente algunas de las preocupaciones actuales vinculadas con los problemas y riesgos que dicha tecnología genera. Por último, trato de

1. El último libro de Manuel Atienza expresa esta idea, como así también la necesidad de pensar el Derecho como cultura jurídica. Ver: ATIENZA, 2020. 
caracterizar e identificar las notas típicas de la ideología transhumanista. El método de abordaje es la contraposición ética entre el Derecho humanista y el transhumanismo. Por razones de extensión, me ciño únicamente al contraste ético y valorativo, por lo que dejo para otra ocasión el problema epistemológico y ontológico. ${ }^{2}$

\section{Inteligencia Artificial y bioderecho}

Lee Sedol no pudo ocultar su tristeza cuando perdió (4 a 1) con AlphaGo, el programa dotado con Inteligencia Artificial desarrollado por DeepMind de Google, en el juego Go.

Pero, como bien señala Mark Coeckelbergh, la Inteligencia Artificial no se limita únicamente a los juegos o al entretenimiento; su aplicación está generalizada e integrada en forma invisible en numerosas herramientas que operan en la vida cotidiana de las personas. El procesamiento veloz de gran cantidad de datos, la conexión a internet, la interacción con los dispositivos móviles, la información que obtiene de allí y de las interacciones en redes sociales, como así también su capacidad de aprendizaje, ha permitido que la Inteligencia Artificial asuma el control de gran parte de nuestras actividades (trabajo, salud, transporte, seguros, finanzas, educación, producción de bienes, etc.) y tome decisiones (Coeckelbergh, 2021, 13).

\section{1. ¿Qué es la Inteligencia Artificial?}

Para la Comisión Europea, se trata de "máquinas o agentes capaces de observar su entorno, de aprender, y basados en el conocimiento y la experiencia adquirida, de tomar acciones inteligentes o proponer decisiones" (Comisión Europea, 2018, 19). ${ }^{3}$

Esta conceptualización tradicional se puede completar con el Anteproyecto de Recomendación sobre la ética de la Inteligencia Artificial de la UNESCO, que la define como "sistemas tecnológicos capaces de procesar información de una manera que se asemeja a un comportamiento inteligente, y abarca generalmente aspectos de razonamiento, aprendizaje, percepción, predicción, planificación o control." ${ }^{4}$

Esta extraordinaria "inteligencia”, con capacidad para procesar gran cantidad de "datos", clasificarlos, interpretarlos y sobre esa base elaborar cursos de acción y ejecutarlos,

2. Con Pérez Luño, vale recordar que la confrontación entre humanismo y poshumanismo se puede realizar desde los tres grandes interrogantes filosóficos: “¿Cómo se conoce la realidad? ¿Qué son y cómo se explican el mundo y la vida? ¿Cuál es la mejor forma de vivir? A esas preguntas han respondido respectivamente, la gnoseología (la teoría del conocimiento, la epistemología, la lógica, la metodología...), la ontología y la deontología o la ética." (Pérez Luño, 2021, 295).

3. La traducción citada del documento de la Comisión Europea, Artificial Intelligence. A European Perspective, Publications Office, Luxembourg es propia "Traditionally, Artificial Intelligence (Al) refers to machine or agents that are capable of observing their environment, learning, and based on the knowledge and experience gained, taking intelligent action or proposing decisions."

4. Ver documento UNESCO. Anteproyecto de Recomendación sobre la ética de la Inteligencia Artificial, SHS/BIO/AHEG-AI/2020/4 REV.2, París, 7 de septiembre de 2020, punto I"Ámbito de aplicación", párrafo 2. 
afecta la autonomía individual y relacional de las personas humanas. El modo en que lo hace es a través de la afectación de la voluntad, que está condicionada (no es libre) por las opciones que ofrece la tecnología, elaborada sobre la base del Big Data (datos ${ }^{5}$ masivos o a gran escala). Éste es, quizá, el llamado a la reflexión jurídica más urgente, dado que golpea con fuerza en el núcleo del Bioderecho internacional: la dignidad humana.

Además, es importante tener presente la clasificación más usual de Inteligencia Artificial, que discrimina entre "IA débil" e "IA fuerte" (o general). Por la primera se entiende a los modelos informáticos que simulan ciertos procesos mentales (IA simbólica) o cerebrales (IA subsimbólica). Para la segunda, también son modelos informáticos, pero, a diferencia de la anterior, no son parciales. La IA fuerte o general no simula algún tipo especial de inteligencia en particular, sino"la mente o el cerebro en su totalidad (IA humana) o bien sólo la conducta producida por ellos (IA ajena)" (Carabante López, 2014, 45).

Una vez conceptualizada, clasificada y detectado el problema mayor, corresponde ahora identificar qué herramientas jurídicas tenemos al alcance.

\section{Bioderecho internacional}

Los materiales jurídicos con los que contamos para hacer frente a los riesgos y problemas que genera la Inteligencia Artificial, en general son los que integran el sistema internacional de derecho humanos, y en particular los que dan cuerpo o componen el Bioderecho internacional. ${ }^{6}$ En concreto, me refiero básicamente a las tres Declaraciones Universales específicas de la UNESCO: sobre el Genoma Humano y los Derechos Humanos, de 1997; sobre los Datos Genéticos Humanos, de 2003; y sobre Bioética y Derechos Humanos, de 2005, todas en concordancia con la Declaración Universal de los Derechos Humanos de la ONU, de 1948. Cabe destacar que estos instrumentos normativos son aplicables en el ámbito Regional Interamericano, pues conforman el corpus iuris internacional aplicable, de acuerdo con la interpretación dada por la Corte Interamericana de Derechos Humanos. ${ }^{7}$ Desde luego, si el Anteproyecto de la UNESCO sobre ética de la Inteligencia Artificial adquiriese el rango de Declaración, también deberá integrárselo a este corpus, sin perjuicio de que cabe otorgarle por el momento un alto valor dogmático.

5. La definición que aporta la RAE respecto al término "dato", en su tercera acepción, es la siguiente: "Información dispuesta de manera adecuada para su tratamiento por una computadora." (www. rae.es)

6. Para ampliar ver García San José, 2010.

7. "El corpus juris del Derecho Internacional de los Derechos Humanos está formado por un conjunto de instrumentos internacionales de contenido y efectos jurídicos variados (tratados, convenios, resoluciones y declaraciones). Su evolución dinámica ha ejercido un impacto positivo en el Derecho Internacional, en el sentido de afirmar y desarrollar la aptitud de este último para regular las relaciones entre los Estados y los seres humanos bajo sus respectivas jurisdicciones. Por lo tanto, esta Corte debe adoptar un criterio adecuado para considerar la cuestión sujeta a examen en el marco de la evolución de los derechos fundamentales de la persona humana en el derecho internacional contemporáneo." (Opinión Consultiva 16/99, párr. 115). 
Las reglas y principios que componen el objeto del Bioderecho se pueden resumir en los siguientes: a) dignidad de la persona humana; b) protección de la diversidad; c) igualdad; d) no discriminación; e) libertad o autonomía; f) derecho a la identidad personal, grupal, nacional y regional; g) derecho a la biodiversidad; $h$ ) derecho a la confidencialidad; i) principio de no-comercialización del cuerpo humano; j) derecho a saber (o a no saber); k) derecho a la salud; l) principio de atención, respeto y protección de las personas humanas en situación de vulnerabilidad; II) principio de libre investigación científica; $m$ ) principio de conservación y aprovechamiento sostenible de la diversidad biológica y del medio ambiente; $n$ ) principio de protección de las generaciones futuras (Figueroa Yañes, 2021); entre otros.

\section{Dignidad humana}

Según se desprende del detalle anterior, se puede pensar con razón, que todas las reglas y principios aludidos desde el segundo lugar en adelante, de una u otra manera son tributarios del primero, ya que la "dignidad humana" les confiere validez y legitimidad. Y ello es así en razón del vínculo conceptual interno que une a la dignidad humana con los derechos humanos. En efecto, como sostiene Habermas, la dignidad no es únicamente una expresión clasificatoria, "como si se tratara de un parámetro de sustitución vacío que agrupara una multiplicidad de fenómenos diferentes" (Habermas, 2010, 6). Para este autor, la dignidad constituye el sustento (moral) de los derechos fundamentales, a la vez que cumple una función "catalizadora" en la construcción de derechos humanos en términos conceptuales y en la forma de establecimiento como derechos subjetivos (Habermas, 2010, 6).

A pesar de que dignidad humana es una noción difusa, generalmente se acepta que el sentido más próximo que le otorgan los textos normativos es el kantiano. Por eso, pensar en el respeto de la dignidad humana de una persona equivale a pensar en el respeto de la humanidad misma. De igual modo, que las acciones del agente responden a su capacidad de actuar con autonomía, de darse a sí mismo la legislación, en suma, a su condición de sujeto moral racional. Lo que expresa una moral racional es la voluntad incondicionada del agente, y en la relación con el "otro" (intersubjetividad) impide tratarlo "únicamente" como medio. Esta buena voluntad implica no sólo el deber para con el otro sino también con un mismo (nociones de respeto y autorrespeto). ${ }^{8}$

Para Garzón Valdés, la dignidad es una "etiqueta adscripta"; "una propiedad distintiva atribuida exclusivamente a todo ser humano viviente" (Garzón Valdés, 2006). Ello significa que es independiente de su capacidad de ejercicio. El hecho de que el concepto de dignidad humana tenga carácter adscriptivo, significa que no es meramente descriptivo. Dicho de otro modo, si bien decir que un ser $\mathrm{X}$ tiene dignidad presupone

8. La segunda formulación del imperativo categórico así lo expresa: “Obra de tal modo que uses a la humanidad, tanto en tu persona como en la persona de cualquier otro, siempre al mismo tiempo como fin y nunca simplemente como medio." (Kant, 2012, 139, A67). 
la verdad del enunciado descriptivo (que afirma que $X$ es un ser viviente perteneciente a la especie humana), tal presuposición arrastra el carácter adscriptivo. Se trata de una adhesión conceptual. Por tanto, sería contradictorio decir que $X$ pertenece a la especie humana y está vivo, y a la vez sostener que carece de dignidad. Se trata de una "carga moral positiva" del concepto (Garzón Valdés, 2006). En suma, el sujeto con dignidad (la persona humana viva) no es negociable (no tiene precio) y tal dignidad es inviolable. A este sujeto protege el Bioderecho internacional.

\section{Lo personal es político}

Ahora bien, llegados a este punto, conviene resaltar que el problema más importante que provoca la Inteligencia Artificial, la afectación sobre la autonomía personal y relacional presenta dos rasgos específicos, que lo diferencian de otras inequidades: es global e indiscriminada. Es decir, el Derecho no se enfrenta a problemas de justicia respecto de personas pertenecientes a colectivos determinados (género, edad, raza, orientación sexual, religión), o ciudadanos de un determinado país o región (migrantes). El conflicto atañe a los condicionamientos sobre la voluntad de toda la humanidad. Al menos de aquella expuesta a la tecnología, que es su gran mayoría.

Y este condicionante a la libertad individual, por la propia dinámica y capacidad de decisión de la infotecnología, se propaga a lo colectivo. El escándalo de Cambridge Analytica es un claro ejemplo de ello.

Por eso, como bien enseña la filosofía feminista, en este caso lo personal también es político. De allí que sea prudente admitir que nuestra capacidad para intervenir e influir en las decisiones colectivas está disminuyendo, para pensar en estrategias que contrarresten la debilidad de la posición. En lo que atañe al Derecho, una salida no utópica consistirá en el establecimiento de límites de actuación de la Inteligencia Artificial. En la práctica, ello se traduce en el ejercicio de control de los datos personales por cada interesado, a través del establecimiento de recursos técnicos para suprimirlos o modificarlos, sin que para ello se deba recurrir a mecanismos jurisdiccionales. Como ya se dijo, la Inteligencia Artificial se nutre de la masividad de datos. Y dado que no es posible para la mayor parte de las personas trabajar sobre la programación de dicha tecnología, se deberían establecer mecanismos ágiles, asequibles a los legos informáticos, para cortar su fuente de abastecimiento.

Lo que hacemos a diario con los dispositivos conectados a internet trascienden la faz privada del individuo. Nuestros datos personales son la materia prima de las interpretaciones y decisiones generales de la Inteligencia Artificial, en las cuales no intervenimos. Al menos no lo hacemos en el sentido democrático de participación social y política consciente. Con la ayuda de la Inteligencia Artificial, empresas y gobiernos capturan y procesan nuestros datos y preferencias, elaboran perfiles, nos clasifican en categorías y generan productos de mercado y electorales acorde a las conclusiones algorítmicas. La influencia sobre nuestra intimidad, entonces, excede la recomendación del filme o playlist que aparecerá en la plataforma audiovisual. Se traslada a las cuestiones más 
significativas, centrales de la condición humana, como las vinculadas con las decisiones políticas. Lo mismo sucede con otras relacionadas con la salud, el trabajo o incluso en las relaciones de pareja. De modo que nada más político que nuestro ámbito de privacidad publicitado por la infotecnología.

Vale insistir en el llamado de atención, porque el riesgo concreto es que emerja una "gubernamentabilidad algorítmica" global que, "a escondidas", como sostiene Sadin, gobierne nuestras realidades colectivas e individuales. Esta gobernanza algorítmica en aumento es una forma de "administración electrónica de la vida, cuyas intenciones de protección, de optimización y de fluidificación dependen en los hechos de un proyecto político no declarado, impersonal, aunque expansivo y estructurante" (Sadin, 2018, 137-138).

Se puede apreciar entonces que los problemas y riesgos son políticos, jurídicos y éticos, como sucede cada vez que se afecta nuestra autonomía.

Tal vez no sea posible en nuestra contemporaneidad volver a dibujar las fronteras que discriminan las esferas de lo íntimo, privado y público. Pero vale la pena el esfuerzo de atemperar los efectos negativos de su indeterminación precisa. Nuestra intimidad significa -sigo aquí a Garzón Valdés- ser dueños de nuestros pensamientos, la zona donde tomamos nuestras decisiones, cuya eventual realización no requiere la intervención de terceros, ni los afecta. En este espacio, ninguna intromisión estará justificada, de allí que deba resguardarse su accesibilidad pública. En el otro extremo está lo público, donde los comportamientos y decisiones de las personas deben ser de libre accesibilidad. Para el caso de que éstas detenten además un cargo dotado de autoridad política, este elemento publicista será también esencial a la consolidación del Estado de Derecho. En una zona intermedia se encuentra lo privado. En palabras del autor:

"La privacidad es el ámbito donde pueden imperar exclusivamente los deseos y preferencias individuales. Es condición necesaria del ejercicio de la libertad individual. Parafraseando a Amartya Sen, podría decirse que la privacidad es la "esfera personal reconocida".... Cuáles sean los límites de la privacidad es algo que depende del contexto cultural y social... [es el]ámbito reservado a un tipo de situaciones o relaciones interpersonales en donde la selección de los participantes depende de la libre decisión de cada individuo" (Garzón Valdés, 1998; Garzón Valdés, 2003).

\section{El Bioderecho como forma de resistencia del poder aletheico de la Inteligencia Artificial}

De acuerdo con lo expuesto, la manera que la cultura jurídica encuentra para encarar las problemáticas y riesgos de la Inteligencia Artificial es recurriendo al Bioderecho. Este encuentro entre Bioética y Derecho tiene bases normativas lo suficientemente sólidas, como para abordar las diferentes y complejas problemáticas, éticas y jurídicas, a las que nos expone la infotecnología y las ideologías no humanistas, que se desarrollan bajo su amparo. Dado que esta tecnología (IA) opera en forma oculta afectando la voluntad libre del sujeto, es razonable que el Derecho y la Bioética no trabajen en forma aislada, sino coordinadamente, a fin de encontrar una salida integral y legitimada. 
Este problema, que como vimos no sólo afecta la autonomía personal y relacional, sino también el espacio político, tiene a su vez un efecto estructural en la personalidad, dada la injerencia en la construcción y capacidad de modificación de la propia biografía (identidad).

Todo lo dicho se relaciona con el carácter aletheico de la Inteligencia Artificial, esto es, con su poder de "decir verdad". En un trabajo anterior (Juan, 2020ª) sostuve que el Bioderecho se puede justificar con una construcción ética basada en la integración de distintos postulados teóricos de éticas humanistas. En concreto, se trataría de una suerte de colaboración que respete el principio de responsabilidad (Jonás, 1995; Jonás, 1997), en un contexto de discurso (Habermas, 1985; Habermas, 2002), y asuma a su vez la mirada del agente de la ética del cuidado (Gilligan, 2003; Gilligan, 2013).

Además de la justificación normativa, con ello se contribuiría, razonablemente, a resistir el embate de postulados poshumanistas o transhumanistas. Estas corrientes de pensamiento agregan al fenómeno infotecnológico otras cuestiones vinculadas con la biotecnología (Ingeniera Genética). El fenómeno completo es objeto de tratamiento del Bioderecho.

Dado que en aquel trabajo ya me detuve en la descripción y caracterización de la Inteligencia Artificial, como así también en la propuesta ética humanista colaborativa, en lo que sigue propongo la caracterización del pensamiento transhumanista.

\section{III. ¿UNA HISTORIA TRANSHUMANA?}

A modo introductorio me permito presentar una historia literaria. En Londres, en los años ochenta del siglo pasado, luego de que Inglaterra perdiera la guerra de Malvinas, el científico Alan Turing (no era verdad que se había suicidado a mitad de siglo) estaba exaltado por la nueva tecnología. Se habían lanzado al mercado los primeros prototipos de "seres humanos sintéticos", dotados con Inteligencia Artificial. Una primera edición limitada la conformaban doce "Adanes" y trece "Evas". La trama de la novela de lan McEwan, "Máquinas como yo y gente como vosotros" (McEwan, 2019), comienza cuando uno de los protagonistas "humanos" (Charlie) adquiere un "Adán", y solicita a su pareja (Miranda, quien vivía en otro departamento, en el piso superior) que lo ayude a programarlo. Lo harían conforme las preferencias de ambos. ${ }^{9}$

"Lo anunciaban como compañía, como pareja intelectual con quien medirse, como amigo y factótum capaz de fregar los platos, hacer la cama y «pensar». Era capaz de registrar y recuperar cada momento de su existencia, cada cosa que oía y veía. De momento no sabía conducir y no se le permitía nadar o ducharse o salir los días de lluvia sin paraguas, o manejar una motosierra sin supervisión. En cuanto a autonomía, y gracias a los grandes avances en el almacenamiento eléctrico, podía correr diecisiete kilómetros en dos horas sin necesidad de recarga, o, en su equivalente en energía, conversar sin descanso durante doce días. Su vida útil era de veinte años. De complexión compacta,

9. Esta novela fue objeto de un anterior análisis, desde la perspectiva "Derecho en la Literatura" (Juan, 2020b). 
hombros cuadrados, piel oscura y pelo negro tupido peinado hacia atrás; de cara estrecha, con un toque de nariz aguileña que sugería una aguerrida inteligencia, párpados caídos y meditabundos, labios apretados que, en aquel mismo momento, mientras le estábamos mirando, se vaciaban de su cadavérico tinte blanco amarillento y adquirían un rico color humano, e incluso se relajaban un poco en las comisuras. Miranda dijo que parecía «un cargador de muelle del Bósforo».

[...]No podía pensar en mí como el «usuario» de Adán. Había dado por sentado que nada podía aprender de él que él mismo no pudiera enseñarme. Pero el manual que tenía en las manos se había abierto en el capítulo catorce. El lenguaje, en él, era sencillo: preferencias, parámetros de personalidad. Luego una serie de epígrafes: Amabilidad, Extraversión, Apertura a la experiencia, Escrupulosidad, Estabilidad emocional. La lista me era familiar. El modelo cinco factores." (McEwan, 2019, 14-17).

Este relato de McEwan, cuya lectura cabe recomendar, no está tan alejado de la realidad. En efecto, el también robot antropomorfo Sophia posee simulaciones de los músculos más importantes del rostro humano, con los que es capaz de realizar movimientos que expresan alegría, pena, curiosidad, confusión, contemplación, pesar y más. El fundador de la empresa que lo produjo ha dicho: "Todavía no lo logramos del todo, pero Sophia puede representar varios estados emocionales y también puede ver las expresiones emocionales en el rostro humano".10

Otra agencia de noticias expone el mismo caso. A la pregunta “Cómo estás, Sophia?", el robot respondió "feliz", al tiempo que esbozaba una "amplia sonrisa." Cuando llegó el turno de Han, el "hermano" de Sophia, se le preguntó si deseaba obtener la ciudadanía de un país, a lo que respondió: "A la velocidad con la que los humanos están estropeando este mundo, quizá sea mejor esperar y obtener la ciudadanía robótica. Y esta vez no bromeo."11

Es verdad, no bromeaba. Al menos a su "hermana" ya le otorgaron la ciudadanía saudita. ${ }^{12}$

\section{El caso del cíborg}

Uno de los sentidos habituales dados a la Inteligencia Artificial es el de "tecnología convergente". Ello significa que su análisis se realiza desde su conexión con la biotecnología, la nanotecnología (tecnociencias) ${ }^{13}$ y las ciencias cognitivas.

10. https://expansion.mx/tendencias/2019/01/05/sophia-el-robot-que-rie-sonrie-y-frunce-el-ceno-como-tu

11. https://www.efe.com/efe/america/tecnologia/las-ineditas-emociones-del-robot-sophia-fascinan-a-la-web-summit/20000036-3806083

12. https://www.bbc.com/mundo/noticias-41803576

13. La Biotecnología "se define como «la aplicación de la ciencia y la tecnología a los organismos vivos, así como a partes, productos y modelos de los mismos, para alterar materiales vivos o no, con el fin de producir conocimientos, bienes o servicios»”" (Escajedo San Epifanio, 2021). Por su parte, "La nanotecnología es una ciencia aplicada al diseño, síntesis y empleo de materiales e instrumentos a escala atómica y molecular que establece enlaces entre ámbitos científicos tradicionalmente separados -como física, química y biología- y que tiene un impacto sobre la vida de las personas y el medio" (Casado González, 2021). 
En este marco, el "Adam" de McEwan o el robot "Sophia" de Hanson Robotics, nos permiten pensar si es posible otorgar algún estatus jurídico a los entes artificiales dotados con IA. En este sentido, un caso especialísimo se presenta con el cíborg o cyborg. ¿Es posible que esta entidad posea algún tipo de "autonomía" y que, por lo tanto, deba otorgárseles una personalidad jurídica específica? ${ }^{14}$

Intentar una respuesta para este interrogante implica conceptualizar la entidad. Si por cíborg entendemos a las personas humanas a quiénes se les implantó un determinado equipamiento tecnológico, dotado de Inteligencia Artificial, es decir, una interfase que les permita superar límites físicos o cognitivos, la respuesta sería negativa. La razón es evidente, la persona no pierde su condición humana por la sola instalación de una prótesis. La tecnología vendría a cumplir la función de apoyo que supliría alguna discapacidad.

En cambio, si se considera que el cíborg es una entidad que se libera del cuerpo y todas sus debilidades, para continuar viviendo luego en un soporte artificial, sea éste virtual o mecánico (Palmerini, 2017, 93), la cuestión es más compleja. En este caso, la respuesta también es negativa, pero por dos razones diferentes. La primera tiene relación con el problema filosófico general del significado del cuerpo; si somos cuerpo o tenemos cuerpo, y todas las derivaciones que conlleva dicho interrogante. Al respecto, quizá pueda resultar de ayuda la idea que "La condición humana es corporal. El mundo sólo se da bajo la forma de lo sensible. En el espíritu no existe nada que antes no haya estado en los sentidos" (Le Breton, 2009, 21). Si la condición humana es corporal, la simulación de lo sensible no la suplanta. La mayor o menor capacidad de "engaño" del robot en relación con los sentidos y emociones no lo convierte en humano. La materialidad de "Adam" o "Sophia" no "es" cuerpo humano en el sentido indicado. La segunda razón se refiere a que, si bien la Inteligencia Artificial es capaz de simular el pensamiento humano, y asumiendo por hipótesis que a ello se reduce la racionalidad de nuestra especie, la tecnología carece de ética. Y ello es así debido a su condición de entes "no conscientes", hecho innegable, pues, como bien señala Martino, no es posible trasladarles la sinergia de la mente humana. ${ }^{15}$

En pocas palabras, esta segunda concepción de cíborg nos coloca fuera de la persona humana, más cercana al "Adam" de McEwan o al robot "Sophia", es cierto, pero alejada de la humanidad que significa corporeidad, conciencia y acción moral.

Transhumanismo

Antes de conceptualizar el transhumanismo, vale aclarar que se suelen distinguir las corrientes de pensamiento poshumanistas de las transhumanistas.

Así, Antonio Pérez Luño refiere que mientras los poshumanistas postulan la superación de la humanidad por una especie de "superhumanidad", que estaría causado por el

14. Se puede ampliar en: Marinho Amorim y Cardoso, 2019.

15. Antonio Martino sostiene:"Actualmente, es imposible transferir a las máquinas las sinergias de implementación de la mente, típicas de los humanos, porque la inteligencia electrónica y los cuerpos mecatrónicos trabajan con mecanismos que son diferentes de los biológicos." (Martino, 2020, 12). 
desarrollo tecnocientífico, los transhumanistas sólo defienden el mejoramiento humano, no la suplantación de la persona (Pérez Luño, 2021, 293).

Por su parte, Anna Bugajska y Lucas Misseri parten de una clasificación del poshumanismo, que presentaría dos visiones: una "antropocéntrica" y la otra "anti antropocéntrica". La primera defiende el mejoramiento humano a través del incremento de determinadas características, mientras que la segunda se vincula con el cambio cualitativo de lo humano, tal como lo entendemos en la actualidad. En la perspectiva antropocéntrica, los autores ubican a la corriente "transhumanista", cuya característica está dada por el principio de continuidad evolutiva. Es decir, se piensa en una diferencia de grado y no de clase. La Inteligencia Artificial fuerte o general se incluye en esta categoría. En la visión anti antropocéntrica distinguen a su vez dos tipos de poshumanismos. Por un lado, el "especulativo", donde el nuevo ser es un producto del ensamblaje de sistemas sociales, biológicos y tecnológicos, cuyo rasgo es la codependencia de todas las partes ensambladas. Por el otro, el "crítico", para quienes los humanos son entidades meramente reemplazables (Bugajska y Misseri, 2020).

Sin perjuicio de lo interesante de estas clasificaciones, el transhumanismo admite dos dimensiones: una "moderada" y la otra "radical o extrema".

A modo de concepto general, por transhumanismo se entiende a aquella doctrina que promueve la mejora de la condición humana, conforme lo posibilita la convergencia del desarrollo tecnocientífico actual (biotecnología, nanotecnología) y la Inteligencia Artificial. Este sentido disciplinar "convergente" eventualmente permitiría, en estadios más avanzados, tanto la nanotecnología molecular como la "subida" o utloading -transferencia de la mente humana a un ordenador- (Bostrom, 2011, 169-170). Y con la adquisición de estas nuevas capacidades, sostienen, se permitiría superar la "limitación a la vida" y conseguir "la felicidad humana" (Bostrom, 2011, 158). Se trata entonces de un "mejoramiento" que se lograría por hibridación; entre nuestra existencia natural, la inteligencia artificial (Campione, 2019), y las tecnociencias. Cabe poner de relieve, que las mejores capacidades no se vinculan únicamente con los aspectos físicos y cognitivos, sino también con los emocionales. Es decir, la Inteligencia Artificial colaboraría en la producción de individuos psicológicamente "equilibrados".

Una versión extrema o radical de esta corriente sostiene que es inevitable la superación y trascendencia de la especie humana, lo que dará paso a un nuevo ser "poshumano". El transhumanismo sería una etapa intermedia y necesaria en el recorrido desde lo humano hacia lo poshumano. Esta posición no sólo es descriptiva, sino también normativa, es decir, sus teóricos sostienen que esta posibilidad convergente estaría justificada, para lo cual es menester pensar un derecho mínimo, que no obstaculice el desarrollo tecnocientífico.

La característica principal de esta posición radical es el concepto "singularidad". Esta noción, que literalmente significa "separación o distinción de lo común",16 se basa en otros dos conceptos: "innovación tecnológica continuada" y "crecimiento exponencial"

16. Segunda acepción de la RAE; https://dle.rae.es/singularidad 
de las tecnologías, que en el futuro provocarán la "discontinuidad" de la humanidad. A tal fin, descuentan que en pocos años existirán máquinas dotadas de Inteligencia Artificial fuerte. Vernor Vinge, el creador del concepto "singularidad tecnológica", sostiene que es tal posibilidad tecnológica, la que acarreará como consecuencia el fin de la era humana (Vinge, 1993). Para la posición transhumanista radical, la singularidad tecnológica alcanzará su apogeo en una "civilización tecnológica", producto de la aceleración tecnocientífica, donde resultará imposible predecir sus consecuencias (Burguet Castell, 2017).

Esta perspectiva transhumanista radical aparece cuanto menos contradictoria, y por lo tanto injustificada. En efecto, resulta difícil admitir que una ética humana, cualquiera fuera, pregone acerca de las bondades de un sistema normativo para cuando su era haya terminado. Tampoco es posible determinar nociones de lo bueno o debido, en razón de que no es factible establecer cuáles serán las consecuencias de los actos de la tecnología.

\section{A) Algo no tan nuevo}

La búsqueda de trascendencia de la humanidad no es algo nuevo. Algunos autores transhumanistas recurren a la Épica de Gilgamesh (aproximadamente 1700 a.C.), dónde ya se daba cuenta del anhelo de inmortalidad, de la lucha de la humanidad contra la muerte. ${ }^{17}$

El término también aparece en la Divina Comedia ("trashumanar"). ${ }^{18}$ En forma habitual, el sentido dado al verso de Dante es el de elevarse más allá de los límites de la naturaleza humana. No obstante, conviene advertir que el prefijo "tras" no se refiere al recorrido desde la humanidad hacia la divinidad, sino al intento de descubrir lo oscuro o misterioso que está detrás de la conciencia humana. O sea, remite a un camino interior, no exterior o trascendente.

También se atribuye a Julian Huxley ${ }^{19}$ haber utilizado por primera vez el vocablo transhumanismo, en algún sentido aproximado al que pretende dársele en la actualidad. Empero, este autor tampoco habla de trascendencia de la especie, sino de su permanencia. Él lo piensa como refuerzo de "su" naturaleza humana; reflexiona sobre las nuevas posibilidades para la persona, pero sin desprenderse de su condición humana (Huxley, 1967). ${ }^{20}$

17. Se pueden ver las versiones de: Silva Castillo, 2000; y George, 2014.

18. "Trasumanar significar per verba non si poria; però l'essemplo basti a cui esperïenza grazia serba" (Dante Alighieri, Paraíso, canto I).

19. Hermano de Aldous, el autor de la novela extraordinaria Un mundo feliz (Huxley, 2017).

20. "La especie humana puede, si lo desea, trascenderse a sí misma -no sólo esporádicamente, un individuo aquí de cierta manera, un individuo ahí de otra- sino en su totalidad, como humanidad. Necesitamos un nombre para esta nueva creencia. Tal vez transhumanismo servirá: el hombre permaneciendo hombre, pero transcendiéndose mediante la realización de nuevas posibilidades de y para su naturaleza humana." 
Desde lo lingüístico, el prefijo "trans" genera alguna confusión, que se traslada a la doctrina transhumanista. Como se sabe, "trans" o "tras" significa tanto lo que está "al otro lado de" como lo que se alcanza "a través de".

Con todo, es importante saber con quiénes deliberamos en el discurso (en el sentido habermasiano) para encontrar un mejor Derecho y su justificación. Si la perspectiva "transhumanista" es un "nuevo humanismo", postmoderno y laico, como afirman algunos de sus defensores (lo que está "al otro lado de" lo humano actual, pero sin perder su condición de tal), es posible establecer un diálogo razonable. Por el contrario, si se piensa el transhumanismo con la idea de trascendencia o de superación de la especie, de alcanzar algo distinto (favorecido por la singularidad), nos topamos con un anti humanismo que dificulta cualquier actividad dialógica. El paso "a través de" implica la abolición del ser humano, y ello poco o nada tiene que ver con una cultura jurídica humanista, que caracteriza al Bioderecho internacional.

\section{B) Entre el humanismo y el antihumanismo}

Siempre desde el espacio de la convergencia entre infotecnología y biotecnología, otra manera de comprender el transhumanismo es a través del análisis de la influencia de la ingeniería genética. Sobre el particular, un sector de esta línea de pensamiento justifica éticamente cualquier accionar destinado a maximizar el bienestar "humano". Con ello, no sólo promueve la manipulación genética destinada al mejoramiento de capacidades, lo que en sí mismo conlleva un aumento de oportunidades, o los tratamientos destinados a la prevención de enfermedades, sino también toda intervención que mejore determinadas características individuales (Savulescu, 2016, 7). Es decir, ponderan la eugenesia positiva. En consecuencia, todas las formas tecnológicamente posibles de decidir sobre nuestros genes y biología son admitidas, no existiendo razón moral -agregan- para limitarlas (Savulescu, 2016, 7). ${ }^{21}$

Este criterio de defensa irrestricta de la libertad de investigación científica, y su consecuente aplicación, no se condice con una ética aplicada de base humanista, ni por lo tanto con el Bioderecho internacional. La falta de justificación moral obedece a la afectación de la autocomprensión revisora del sujeto (Habermas, 2002). En lo que atañe al Bioderecho internacional, porque las disposiciones del corpus jurídico internacional prohíben de forma expresa la intervención genética que no tenga finalidad terapéutica o implique transmisión a la descendencia. ${ }^{22}$ No debe perderse de vista que los valores

21. "There are four possible ways in which our genes and biology will be decided: 1) Nature or God; 2) "Experts" -philosophers, bioethicists, psychologists, scientists; 3) "Authorities" -government, doctors; 4) By people themselves -liberty and autonomy."

22. Ver el Artículo 13 del Convenio para la protección de los Derechos Humanos y la Dignidad del ser humano con respecto a las aplicaciones de la Biología y la Medicina (Convenio de Oviedo). En la Argentina, una disposición interna tiene el mismo sentido. Así, el artículo 57 del Código Civil y Comercial dispone: “Está prohibida toda práctica destinada a producir una alteración genética del embrión que se transmita a su descendencia". 
fundantes de nuestra cultura jurídica, libertad, igualdad y solidaridad, para que respondan al principio rector de la dignidad humana deben trabajar con el balance adecuado. $Y$ este equilibrio no sólo es respecto de las relaciones entre los valores, sino al interior de cada uno. Así es como un ejemplo extraído del ensayo de Allen Buchanan ilustra el problema de otorgar mayor valor a la libertad que a la igualdad, e incluso permite un análisis sobre la desigualdad estructural (en este caso, por razones económicas).

\begin{abstract}
"Katherine y Bill concurren al mismo puesto directivo en una gran empresa. La solicitud de Katherine incluye un certificado de mejoramiento genético de Opti-Gene, el cual establece que su titular ha adquirido un conjunto de servicios genéticos destinados a aumentar la memoria y potenciar el sistema inmunológico. Bill, que no se puede permitir un mejoramiento genético, objeta que un contrato basado en la mejora genética supone una violación de la igualdad de oportunidades: el trabajo debería adjudicarse en función del mérito. Katherine replica que adjudicar el trabajo en función del mérito significa que el puesto corresponde al mejor candidato, y ella es la mejor candidata, de manera que ¿dónde está el problema?" (Buchanan et al, 2009, 4).
\end{abstract}

Para salir de la encerrona, el filósofo sueco Nick Bostrom (2011) realiza una distinción de los tipos de tratamientos con lo que, sin abandonar la posición transhumanista, intenta debilitar la crítica "bioconservadora". Postula como principio que es beneficioso y necesario mejorar la condición humana, no solo mediante acciones sociales y ambientales (cultura, economía), sino también utilizando procedimientos de ingeniería genética. Pero, agrega, dichas mejoras no incluyen las "ventajas" meramente posicionales (v. gr., la altura). Sin embargo, en el planteo la cuestión moral sigue sin estar resuelta. No parece que la solución sea la elaboración de un catálogo contingente de ventajas admitidas (color de ojos, estatura, etc.), sino definir un criterio racional que garantice la autodeterminación del agente, libre de condicionantes decididos en forma previa por terceros.

Este mismo autor, tal vez en el afán de reforzar una posición moderada, sostiene que el transhumanismo no requiere desarrollos extraordinarios o radicales, tales como la superinteligencia (IA fuerte), la nanotecnología molecular o la subida (uploading). Otras realidades que ya están aquí, o lo estarán en las próximas décadas son suficientes. Se refiere a la realidad virtual, el diagnóstico genético pre-implantacional (DGP), la ingeniería genética, los medicamentos que mejoran la memoria, la concentración, la vigilancia y el humor; drogas mejoradoras del rendimiento, cirugía estética, operaciones de cambio de sexo, prótesis, medicina anti-edad, interfaces humano-ordenador más cercanas (Bostrom, 2011). Pero, de nuevo, esta argumentación presenta el mismo problema; no se trata de definir normativamente un menú de opciones, sino un criterio racional para establecerlas.

\title{
C) Los postulados del transhumanismo
}

La Declaración transhumanista, en su última versión del año 2009, se apoya en ocho postulados. Se trata de uno de los documentos fundantes de la Asociación Mundial Transhumanista (WTA, por sus siglas en inglés), cuyos miembros también se denominan "Humanity+", lo que refuerza de alguna manera cierta preferencia por la posición 
menos radicalizada. ${ }^{23}$ No obstante, cabe advertir, sus redactores parecen no cerrar la discusión; al menos, eso se interpreta de la última frase del postulado final, que apoya "muchas otras tecnologías posibles de modificación y perfeccionamiento humano".

En lo que aquí interesa, en su postulado número seis la Declaración destaca:

"La política debe estar guiada por una visión moral responsable e inclusiva, que tome seriamente las oportunidades y los riesgos, que respete la autonomía y los derechos individuales, y muestre solidaridad con y preocupación por los intereses y la dignidad de todas las personas alrededor del mundo. Debemos también considerar nuestras responsabilidades morales hacia las generaciones que existirán en el futuro."24

Con esta base, Bostrom se traza el objetivo de "desarrollar una forma de transhumanismo más madura y académicamente respetable, libre del 'cultismo' que, al menos a ojos de algunos críticos, había afectado a algunas de las reuniones iniciales." (Bostrom, 2011, 174).

En el afán de justificar su doctrina reconoce varias influencias. En primer término, los estudios bioéticos realizados desde los años setenta del siglo pasado, y en especial a partir del desarrollo de las TRHA y las prácticas genéticas. En segundo lugar, recurre a distintas posiciones éticas, entre ellas: la "ética de la población" de Derek Parfit (2004),; el pensamiento de Jonathan Glover; ${ }^{25}$ el "principio preventivo" de Peter Singer (2002, 29); y admite la influencia de la obra de Julián Savulescu (2001). Estos autores, entre otros, permiten a Bostrom elaborar una ética propia que defiende y promueve toda investigación que, en suma, esté destinada a detener el envejecimiento humano (Juan, 2021).

Sobre la base de lo dicho, algunos postulados transhumanistas no radicales pueden ser admitidos desde una perspectiva "humanista", lo que posibilitaría un diálogo destinado al consenso. Tal es el caso del principio sexto aludido (autonomía, derechos individuales, solidaridad, dignidad humana y preocupación por las generaciones futuras).

\section{CONCLUSIÓN: DEFENSA DEL HOMO JURIDICUS}

En la medida que las posiciones transhumanistas no radicales admitan los principios fundantes del Bioderecho internacional y defiendan una ética que no ponga en dudas la permanencia de la humanidad, es decir, que reconozcan que el progreso tecnológico está a su servicio y no a la inversa, es posible debatir racionalmente sobre los límites jurídicos que habrán de regirnos. No es un lujo intelectual ocuparnos de la autonomía

23. Así también se presentan en la web: https://humanityplus.org/

24. "Policy making ought to be guided by responsible and inclusive moral vision, taking seriously both opportunities and risks, respecting autonomy and individual rights, and showing solidarity with and concern for the interests and dignity of all people around the globe. We must also consider our moral responsibilities towards generations that will exist in the future." (ver también Bostrom, 2011, 186-187).

25. "No cualquier aspecto de la naturaleza humana actual [...] merece ser preservado. Más bien, lo son especialmente aquellas características que contribuyen al autodesarrollo y la autoexpresión, a ciertos tipos de relaciones, y al desarrollo de nuestra conciencia y entendimiento. $Y$ algunas de esas características pueden ser ampliadas más que amenazadas por la tecnología." (Glober, 1984, citado por Bostrom, 2011, 177). 
personal y relacional de las personas o del desdibujamiento de las fronteras de intimidad y privacidad, como tampoco lo es ocuparnos de algunas corrientes de pensamiento, por mucho que intuitivamente luzcan descabelladas. Pensar en los riesgos e intentar resolver los conflictos es una necesidad humana que hace a la convivencia social, que en el estado de cosas actual es global, indiscriminada y digital.

El desarrollo infotecnológico y biotecnológico progresó a una velocidad nunca vista. Ni siquiera imaginada. Y no caben dudas que la Inteligencia Artificial y la Ingeniería Genética han superado cualquier previsión de nuestros mayores. Pero ello no nos convierte en dioses (Harari, 2020); sólo se trata de una nueva fase del desarrollo de la ciencia humana, que es un carácter propio de la modernidad inacabada (Habermas, 1993). Nada indica que nos hayamos convertido ni que nos aproximemos a tales entidades omniscientes e inmortales. Por eso mismo sería prudente no utilizar la expresión "jugar a ser dioses", pues su carga emotiva tiende a confundir (aún más) las cosas.

Tampoco somos bestias, en el sentido de seres de desarrollo menor que la Inteligencia Artificial fuerte, y por tanto intercambiables o utilizables como "medios". Por el momento, la posibilidad de ser reemplazados por otras entidades más evolucionadas es una consideración dogmática transhumanista radical tan absurda como improbable. Y en algún punto irresponsable, pues, dado el poder de decir verdad de la Inteligencia Artificial, puede fomentar discursos antidemocráticos. Las ideologías poshumanistas críticas, que consideran a los seres humanos entidades reemplazables por otras más evolucionadas, parten del error de base de simplificar la complejidad humana a un solo aspecto de la racionalidad: la capacidad de cálculo. Las supercomputadoras u otros artefactos o dispositivos informáticos dotados de Inteligencia Artificial Fuerte o General, antropomorfos o no, sin duda pueden ser capaces de realizar operaciones algebraicas mejor y más rápidamente que los humanos. E incluso crear nuevas realidades a partir de deducciones algorítmicas. Pero, en modo alguno, reemplazan la capacidad humana, dado que la tecnología contempla sólo una parcela de nuestra complejidad, racionalidad e inteligencia.

Por su lado, no parece acertada la posibilidad de estipular un estatus específico al cíborg. Si por cíborg se entiende la persona humana que, al estar impedida de ciertas capacidades le colocan implantes artificiales para suplantarlas, no pierde su carácter humano. En este caso, requerirá del Derecho una protección específica, por ejemplo, contra la intromisión en el dispositivo si está conectado a internet, por fallas de producto en el sentido dado por el derecho del consumidor, etc. Por el contrario, si por cíborg entendemos algo distinto al ser humano, una discontinuidad que se reemplaza por un ensamblaje de sistemas sociales, biológicos y tecnológicos, la cuestión se vuelve meramente hipotética, y como se ha visto poco tiene que ver con el Bioderecho internacional y una ética humanista.

De manera que, en tiempos de post y transhumanismos, Inteligencia Artificial e Ingeniería Genética, debemos privilegiar el rescate de la personalidad jurídica del ser humano y nuestra aspiración por la justicia, es decir, nuestra condición de homo juridicus. El artefacto, las creaciones humanas a defender entonces son el Derecho constitucionalizado, la cultura jurídica, los derechos humanos, que desde la Declaración Universal de 1948 nos adscribe, como marca distintiva, la dignidad humana. 


\section{BibliografíA}

Atienza, M. (2020). Una apología del derecho y otros ensayos. Trotta.

Bostrom, N. (2011). Una historia del pensamiento transhumanista. Argumentos de Razón Técnica, 14, 157-191. http://institucional.us.es/revistas/argumentos/14/art_7.pdf

Buchanan, A. et al (2009). Genetics and Justice. Cambridge University Press.

Bugajka, A. y Misseri, L. (2020). Sobre la posibilidad de una ética poshumana: propuesta de un enfoque normativo combinado. Isegoría, 63, 425-449.

Burguet Castell, J. (2017). La singularidad tecnológica, en www.conec.es, Acceso libre: http:// www.conec.es/ciencia/la-singularitat-tecnologica/ Recuperado el: 09/07/2020.

Campione, R. (2019). A vueltas con el Transhumanismo: cuestiones de futuro imperfecto. Cuadernos Electrónicos de Filosofía del Derecho, 40, 45-67. Universidad de Valencia.

Carabantes López, M. (2014). Inteligencia Artificial: Condiciones de posibilidad técnicas y sociales para la creación de Máquinas Pensantes. Tesis doctoral. Universidad Complutense Madrid. Acceso libre en: https://eprints.ucm.es/24630/1/T35134.pdf

Casado González, M. (2021). Enciclopedia de Bioderecho y Bioética. Romeo Casabona, C. M. (Director), Cátedra de Derecho y Genoma Humano. Recuperado el 01.05.2021. https://enciclopedia-bioderecho.com/voces

Coeckelbergh, M. (2021). Ética de la Inteligencia Artificial, trad. Lucas Álvarez Canga, Cátedra, versión e-book.

Escajedo San Epifanio, L. (2021). Biotecnología. Enciclopedia de Bioderecho y Bioética. Romeo Casabona, C. M. (Director), Cátedra de Derecho y Genoma Humano. Recuperado el 01.05.2021. https://enciclopedia-bioderecho.com/voces

Figueroa Yañez, G. (2021). Bioderecho. Enciclopedia de Bioderecho y Bioética. Romeo Casabona, C. M. (Director), Cátedra de Derecho y Genoma Humano. Recuperado el 01.05.2021. https://enciclopedia-bioderecho.com

García San José, D. I. (2010). International Bio Law. Laborum.

Garzón Valdés, E. (2006). ¿Cuál es la relevancia moral del concepto de dignidad humana? Fontamara.

Garzón Valdés, E. (2003). Algunos comentarios sobre lo íntimo, lo privado y lo público. Claves de razón práctica, 137, 14-24.

Garzón Valdés, E. (1998). Privacidad y publicidad. Doxa. Cuadernos de Filosofía del derecho, 21, 223-244.

George, A. (2014). La epopeya de Gilgamesh, trad. Fabián Chueca Crespo, Edición de Bolsillo, versión e-book.

Gilligan, C. (2003). In a Different Voice. Psychological Theory and Women's Development, Thirty-eighth printing, Harvard University Press.

Gilligan, C. (2013). El daño moral y la ética del cuidado. Cuadernos de la Fundació Víctor Grífols i Lucas, 30, 10-39. Edit. Fundació Víctor Grífols i Lucas.

Habermas, J. (1985). Conciencia moral y acción comunicativa. Península.

Habermas, J. (1993). El discurso filosófico de la modernidad (Doce lecciones). Versión castellana de Manuel Jiménez Redondo, $1^{\text {a }}$ ed., reimp. Taurus.

Habermas, J. (2002). El futuro de la naturaleza humana. ¿Hacia una eugenesia liberal?, trad. de R. S. Carbó. Paidós. 
Habermas, J. (2010). El concepto de dignidad humana y la utopía realista de los derechos humanos. Diánoia, vol. LV, 64, 3-25.

Harari, Y. (2020). 21 lecciones para el siglo XXI. Trad. Joandomènec Ros. Debate.

Harari, Y. (2020). Homo Deus. Trad. Joandomènec Ros. Debate.

Huxley, J. (1967). Religión sin revelación. Sudamericana.

Jonas, H. (1995). El principio de responsabilidad. Ensayo de una ética para la civilización tecnológica. Trad. Javier Ma. Fernández Retenaga. Herder.

Jonas, H. (1997). Técnica, medicina y ética: sobre la práctica del principio de responsabilidad. Trad. Carlos Fortea Gil, Paidós.

Juan, G. R. (2020a). Inteligencia Artificial y Filosofía del Bioderecho: una tesis crítica y una propuesta ética. IUS ET SCIENTIA, Vol. 6, 2. https://dx.doi.org/10.12795/IETSCIENTIA Universidad de Sevilla.

Juan, G. R. (2020b). Leer como abogado, abogar como lector. Máquinas como yo, de lan McEwan y la Inteligencia Artificial. Revista de Derecho de Familia, RDF 95, 295, Editorial Abeledo-Perrot (Thomson Reuters-La Ley). Cita Online: AR/DOC/1835/2020.

Juan, G. R. (2021). ¿Transhumanismo o ética humanista? Reflexiones desde la filosofía del bioderecho. Libro colectivo. Facultad de Derecho, Universidad de Buenos Aires (en prensa).

Kant, I. (2012). Fundamentación de la metafísica de las costumbres, trad. Roberto Rodríguez Aramayo, $2^{a}$ Ed. Alianza.

Le Breton, D. (2009). El sabor del mundo. Una antropología de los sentidos, trad. Heber Cardoso. Nueva Visión.

Marinho Amorim, H. y Cardoso, R. C. (2019). O ciborgue no limiar da humanidade: redefinindo a pessoa natural. Revista de Bioética y Derecho Perspectivas Bioéticas, 46, 67-84. Universitat de Barcelona. Acceso público en: www.bioeticayderecho.ub.edu

Martino, A. (2020). 40 Años de inteligencia artificial y derecho: novedades. ¿Por qué se le teme al autómata juez que crearán en Estonia? Astrea. Recuperado el 23.02.2020. https://www. astrea.com.ar/resources/doctrina/doctrina0507.pdf

McEwan, I. (2019). Máquinas como yo y gente como vosotros, trad. Jesús Zulaika, Anagrama.

Palmerini, E. (2017). Robótica y derecho: sugerencias, confluencias, evoluciones en el marco de una investigación europea. Trad. Indira Díaz Lindao. Revista de Derecho Privado, 32, 53-97.

Parfit, D. (2004). Razones y personas, trad. Mariano Rodríguez González. A. Machado Libros.

Pérez Luño, A. (2021). El posthumanismo no es un humanismo. Doxa. Cuadernos de Filosofía del Derecho, 44, 291-312.

Sadin, E. (2018). La humanidad aumentada. La administración digital del mundo. Trad. Javier Blanco y Cecilia Paccazochi, $2^{\text {a }}$ reimp. Caja Negra.

Savulescu, J. (2001). Procreative beneficence: why we should select the best children. Bioethics, 15, 413-426.

Savulescu, J. (2016). Genetic interventions and the ethics of enhancement of human beings. Gazeta de Antropología, 32 (2), artículo 07. Universidad de Granada. http://hdl.handle. net/10481/43310

Silva Castillo, J. (2000). Gilgamesh o la angustia por la muerte (poema babilonio), trad. directa del acadio, $4^{a}$ ed. corregida. El Colegio de México.

Singer, P. (2002). De compras por el supermercado genético. Isegoría, 27, 19-40.

Supiot, A. (2012). Homo juridicus. Ensayo sobre la función antropológica del derecho, trad. Silvio

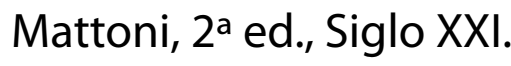

Vinge, V. (1993). The coming technological singularity. Whole Earth Review Winter issue. 